\title{
O ANTEPREDICATIVO EM SEIN UND ZEIT
}

Nelci do Nascimento Gonçalves

SINTESE - Trata-se de mostrar que o interesse lógico do primeiro Heidegger, sobretudo em Sein und Zeit, é guiado pela distinção de princípio entre lógica e lógica produtiva, de forma a traduzir a questão ontológica em termos fenomenológicos e hermenêuticos.

PALAVRAS-CHAVE - Fenomenologia. Hermenêutica. Lógica. Metafísica. Ontologia.
ABSTRACT - This article seeks to show how the logical interest of the early Heidegger, especially in Sein und Zeit, is guided by the principleoriented distinction between logic and productive logic, so as to translate the ontological question in phenomenological and hermeneutical terms.

KEY WORDS - Hermeneutics. Logic. Metaphysics. Ontology. Phenomenology.

Do ponto de vista histórico-crítico, o texto de Sein und Zeit se encontra inserido, como é sabido, no período chamado do jovem, ou do primeiro Heidegger, período que tem início com seus estudos universitários em 1909. Porque se trata da obra que precede ou prepara a Kehre, a publicação de Sein und Zeit, em 1927, é considerada a culminância deste primeiro período. Contudo, seja na chamada primeira fase, seja na chamada segunda fase de seu pensamento, para Heidegger se tratou sempre de investigar uma mesma questão, a questão ontológica, a questão do ser. Por isto, Gadamer afirma que, em Sein und Zeit, Heidegger não abordou a questão do ser de modo completo, somente a preparou.'

Para a formação do jovem Heidegger, concorreram numerosos e diversos elementos que podem ser de ajuda na elaboração de um quadro, a partir do qual seja possivel reconhecer o surgimento, bem como o desenvolvimento da questão predominante ou única de sua pesquisa filosófica. Estes elementos são, por exemplo, o movimento neokantiano dominante na cultura filosófica alemã do início de nosso século, a fenomenologia de Husserl, Aristóteles, Nietzsche, a concepção cristã da história, Kierkegaard, Dilthey, Dostoiewski, Agostinho, Luthero e outros.

Queremos porém focalizar aqui, para efeito de análise, aquele que chamaremos de "interesse lógico" do primeiro Heidegger, entendendo-o como interesse teórico dirigido para problemas lógico-filosóficos. Este interesse aparece já em

1 H. G. Gadamer, Heideggers Weg. Studien zum Spätwerk, Mohr, Tübingen, 1983, p. 23. 
1912, num artigo intitulado Neure Forschungen über die Logik ${ }^{2}$ no qual Heidegger pergunta explicitamente o que vem a ser propriamente a lógica, e retorna nas suas primeiras publicações, entre os anos de 1913 e1916.

A origem do interesse lógico de Heidegger pode ser explicada em relação ao âmbito de questões que eram discutidas tanto no interior da corrente neokantiana, quanto fora dela, pela fenomenologia de Husserl, especialmente nas Logische Untersuchungen ${ }^{3}$. Um exame acurado dos primeiros textos de Heidegger - sua dissertação sobre o juízo no psicologismo $0^{4}$, sua tese de livre docência ${ }^{5}$ e seu trabalho sobre o conceito de tempo na historiografia ${ }^{6}$ - pode mostrar que, inicialmente, seu interesse lógico se desenvolveu sob o influxo da fenomenologia e em polêmica com o neokantismo, mas prosseguiu, se bem que nem sempre de modo explícito, num sentido sempre mais divergente em relação ao trabalho filosófico de seu mestre Husserl.

A continuidade da atenção dada à lógica por Heidegger, pode ser constatada pela sua presença nos cursos que o filósofo ministrou no periodo entre os anos de 1921 e 1927, de modo especial os intitulados Ontologie (Hermeneutik der Faktizität), Logik. Die Frage nach der Wahrheit e Die Grundprobleme der Phänomenologie. ${ }^{9}$ Nestes, a lógica tradicional é tomada em consideração, para ser pensada no sentido de uma lógica filosófica, de uma "lógica produtiva" (produktivLogik), expressão que comparece já no primeiro dos cursos citados, ministrado em Friburg no semestre de verão de 1923, e se encontra presente igualmente em Sein und Zei, no início da obra, quando do exame do primado ontológico da questão do ser.

Lógica produtiva quer dizer, lógica filosófica, uma lógica capaz de produzir, de instituir, conceitos fundamentais que sirvam de guia para as ciências positivas, conceitos estes que não são extraídos da própria lógica mas da interpretação do ente na constituição fundamental do seu ser. Por isto, conceitos fundamentais são fundamentais, e sua investigação antecede a pesquisa das ciências positivas, aquelas ciências voltadas somente para o ente que, a cada vez, é tomado como seu positum. É no sentido de corroborar a possibilidade de investigação de uma lógica produtiva que, por exemplo, em Sein und Zeit, é invocado o testemunho das obras de Platão e de Aristóteles.

2 M: Heidegger, in "Literanische Rundschau für das katholische Deutschland", XXXVIII, Freiburg in Br., 1912, p. 465-472, 517-524, 565-570 (GA I, p. 17-43).

3 E. Husserl, op. cit.

- M. Heidegger, Die Lehre vom Urteil im Psychologismus. Ein kritischpositiver Beitrag zur Logik, Leipzig, 1914 (GA I, p, 59-188).

5 M. Heidegger, Die Kategorien und Bedeutungslehre des Duns Scotus, Tübingen, 1916 (GA I, p. 317).

6 M. Heidegger, Der Zeitbegriff in der Geschichtswissenschaft, in "Zeitschrift für Philosophie und philosophische Kritik", CLXI, Leipzig, 1916, p. 173-188 (GA I, p. 413-433).

7 M. Heidegger, Ontologie (Hermeneutik der Faktizität), Klostermann, Frankfurt a M., 1988 (GA LXIII).

8 M. Heidegger, Logik. Die Frage nach der Wahrheit, Klostermann, Frankfurt a M., 1976 (GA XXI).

- M. Heidegger, Die Grundprobleme der Phänomenologie, Klostermann, Frankfurt a M., 1975 (GA XXIV). 
Com o que assinalamos até aqui visamos mostrar que o interesse lógico do primeiro Heidegger guarda direta relação com a questão ontológica, e que tal interesse lógico culmina em Sein und Zeit, com a distinção de princípio entre "lógica" e lógica produtiva. No primeiro caso, no caso da "lógica", se trata segundo o que escreveu Heidegger, de "um esforço subseqüente e claudicante que analisa o estado momentâneo de uma ciência em seu "método". ${ }^{10}$ A lógica produtiva, por sua vez, é a que apresenta condições necessárias para a fundação das ciências. Tal fundação porém, não é para ser confiada à teoria do conhecimento ou à epistemologia, mas à ontologia; Heidegger diz que a fundação das ciências, se não quiser fechar os olhos diante de sua intenção mais autêntica, só pode ser conduzida através de uma elucidação preliminar da questão do sentido do ser que dê novamente vida à produtividade do passado.

A Filosofia é pois, para Heidegger, ontologia justamente enquanto se encontra voltada, antes de tudo, para o ser, o seu "a priori". Consequentemente, a Filosofia é ciência "a priori" e, como tal, possui um tipo de acesso específico e um modo determinado de apreensão do ser. Disto deriva a originariedade da investigação ontológica frente às pesquisas ônticas das ciências positivas.

De acordo com a concepção heideggeriana de Filosofia, o tema de Sein und Zeit, a questão do ser, é a questão excelente, que deu vida a toda Filosofia, a questão mais antiga e, juntamente, a mais contemporânea para um pensamento que se propõe investigá-la no horizonte do tempo, como questão do sentido do ser em geral. É então somente enquanto questão transmitida pela tradição ontológica que a questão do ser e seu sentido pode ser repetida. Sendo assim, toda investigação sobre o ser é já sempre histórica, no sentido que lhe é inerente um passado. No entanto, este passado antes de mais nada cobre e esconde o que transmite, não somente por um erro ou desvio dependente da tradição, mas porque o velamento pertence ao ser mesmo e inaugura o seu caráter histórico.

Porem, o único e autêntico tema da Filosofia, segundo Heidegger, foi esquecido. A ontologia antiga, através de seus dogmas e de seus preconceitos, teria emudecido a questão do ser e seu sentido como tema explícito de investigação. Ao declarar que entre todos os conceitos o mais geral é o conceito de ser, ao deduzir desta máxima generalidade a impossibilidade de definir o conceito de ser e, ao afirmar sem nenhuma inquietação a obviedade do conceito de ser, a tradição, além de, paradoxalmente defini-lo segundo o gênero próximo e a diferença específica, trivializou a questão do pensamento; tirando-a do velamento que suscitou a inquietação originária do filosofar, a ontologia antiga a transformou num problema metafísico, numa questão já prejudicada ou, dito de outro modo, a ontologia entendida como doutrina do ser em geral teria se tornado o ponto de partida indiscutível da metafísica. Este modo de colocar a questão, teria impedido que o velamento mesmo fosse pensado como manifestação do ser, e a questão teria assim permanecido no esquecimento quanto a seu sentido enigmático. Transmitida

10 M. Heidegger, Sein und Zeit,Niemeyer,Tübingen, 1957, p.10, (GA II), trad.bras. de Márcia de Sá Cavalcanti, Ser e Tempo, Vozes, Petrópolis, 1988, p. 36-37. 
como tal a toda história da metafísica, teria suportado ainda, não só a partir de Platão e Aristóteles, mas além destes, inúmeros desvios e sobrecargas.

Segundo esta perspectiva é que a obra mais importante do primeiro Heidegger requer e inclui o projeto de uma "destruição" (Distruktion) da história da ontologia, à qual é conexa uma intenção positiva: por um lado, ela delimita o campo de investigação de Sein und Zeit, com o que é fixado o âmbito no qual a questão guia deste tratado de ontologia é colocada, por outro lado, a destruição quer submeter a ontologia antiga a uma prova acerca dos seus limites, quer averiguar se ela experimentou o traço mais próprio da manifestação do ser, o seu velamento, e isto através da indagação se, e em que medida, ela teria abordado a questão do ser relacionada ao fenômeno do tempo.

Nesta direção é que, para Heidegger, a ontologia antiga não teria enfrentado de modo radical a diferença ontológica, ao contrário, teria optado por uma doutrina das categorias, uma onto-lógica do ente simplesmente presente, ou do ente simplesmente dado. Com este modo de tratar a questão do ser, ela teria afastado a questão do ser do horizonte do tempo, e, desviado seu olhar do enigma da Seinsfrage, produzindo seus conceitos sem dotá-los das respectivas "certidões de nascimento"11. Por isto, repetir a questão do ser e do seu sentido em geral quer dizer, antes de tudo, colocar a questão ontológica de modo diferente da tradição que a abordou de forma lógico-categorial. Este modo diferente não é, então, estrita ou estreitamente lógico porque é fenomenológico, o que significa que ele visa o ser no enigma de seu sentido. A ontologia fundamental, a ontologia de Sein und Zeit,é assim, fenomenologia, cujo sentido formal é "deixar e fazer ver por si mesmo aquilo que se mostra, tal como se mostra a partir de si mesmo"12.

Sendo assim, Sein un Zeit apresenta uma orientação extraída do antepredicativo, embora o antepredicativo não se encontre nitidamente tematizado por Heidegger em Sein und Zeit. Isto não quer dizer, porém, que se trate de um tema implícito, que um trabalho de exegese devesse esclarecer, como a querer descobrir uma dimensão escondida no texto heideggeriano. Ao contrário, enquanto investiga o sentido do ser em geral, Sein und Zeit pode ser considerada, no seu todo e em todas as suas articulações intemas, uma obra sobre o antepredicativo.

Segundo o que pode ser lido nos parágrafos iniciais da obra máxima de Heidegger, nela questionado é o ser, "o que determina o ente como ente"13 e que exige um modo próprio de demonstração essencialmente diferente da descoberta do ente; perguntado é o sentido do ser que, por sua vez, requer uma conceituação própria e diferente dos conceitos que determinam o significado do ente; em fim, à tematização explícita da questão do sentido do ser, é necessária a explicação prévia do interrogado quanto a seu ser.

Interrogado é o Dasein, ente privilegiado, que goza, de uma primazia porque, mesmo do ponto de vista de uma consideração ôntica, ele não é redutível a um

\footnotetext{
Cf. SZ, §6; ST, §6.

M. Heidegger, SZ,p. 34: ST, p. 65.

M. Heidegger, SZ, p.6; ST, p. 32.
} 
ente dentre outros. A característica do ente privilegiado, durante o tempo em que ele é, é a de manter relação com seu ser: o Dasein se distingue dos demais entes porque a compreensão de ser lhe pertence, porque este é seu modo de ser. Por isto, a primazia do Dasein não é somente ôntica, é também ontológica, o que quer dizer que, este ente não é abordado, em Sein und Zeit, mediante categorias lógicas mas tendo por base a diferença ontológica.

Não se trata portanto, de determinar a quididade do Dasein, menos ainda, de elencar suas possíveis modificações. O Dasein não é determinado categorialmente, não lhe pertence uma essência se, por esta, entendemos alguma coisa que subsiste ou persiste; também não lhe pertence uma existência, se nos limitarmos a entendê-la como uma realidade efetiva. Tais categorias pertencentes à ontologia tradicional são, por Heidegger, radicalmente deslocadas para obtenção do conceito formal de existência: "O Dasein é um ente que, na compreensão de seu ser, com ele se relaciona e comporta".

Uma vez que, o ente privilegiado se caracteriza pelo privilégio compreensivo, ele se relaciona com o que é questionado pela ontologia, segue-se daí que a analítica da existência se configura então, como via necessária a ser percorrida pela ontologia fundamental. Com isto, ela nada mais é do que a radicalização da compreensão pré-ontológica do ser pertencente ao Dasein.

Mas, a compreensão da existência, à qual o Dasein tem acesso somente existindo, é por Heidegger nomeada de compreensão existenciária (existenzielle), ela é portanto, pré-temática, pré-fenomenológica, pré-ontológica, pré-teórica. Esta mesma compreensão pode ser esclarecida através de uma abordagem fenomenológica, teórica, com o que, se trata, para Heidegger, da existencialidade (Existenzialität). A análise fenomenológica da existencialidade tem, assim, caráter de uma compreensão existencial (Existenzial) e não existenciária ${ }^{14}$; no entanto, devemos enfatizar, é esta última que se constitui em base fenomenal, em solo prétemático, em condição de possibilidade portanto, da analítica da existência no texto heideggeriano, sendo ela, consequentemente, condição de possibilidade da própria ontologia de Sein un Zeit, compreendida como questionamento teónico explícito do sentido do ser em geral.

No que se refere ao exame teórico da constituição do modo de ser do Dasein, também este não é lógico, porque é fenomenológico-hermenêutico, o que quer dizer, descrição a partir da própria coisa que deve ser descrita, interpretação. 0 sentido formal de fenomenologia gera então a concepção metodológica que norteia a analítica existencial, que se encontra voltada para o fato específico da existência do Dasein, para a facticidade (Faktizität) de seu ser-no-mundo, a fim de explicitar o privilégio compreensivo deste ente, privilégio este que não é lógico mas, ontológico.

Uma vez que, o Dasein é ser-no-mundo, a elaboração conceitual do fenômeno do mundo necessita ingressar nas estruturas fundamentais da existência, porque

14 Cf., $S Z, \S 4$. 
tal elaboração não tem em vista somente descrever o fenômeno do mundo, ela visa com esta descrição alcançar sua estrutura essencial que se encontra arraigada na existência do ente que é ser-no-mundo. Assim, o problema do mundo, em Sein und Zeit, se encontra conexo com as estruturas fundamentais da existência, com a disposição (Befindlichkeit), com a compreensão (Verstehen), com a interpretação (Auslegung) e com o discurso (Rede), enquanto estes são modos característicos de ser do Dasein. Nesta direção é que o mundo é o a priori do Dasein, não há Dasein sem mundo, menos ainda mundo sem Dasein. Às interpretações que não consideram o mundo como constitutivo do ser do Dasein, resta somente, segundo Heidegger, tomar um certo ente, a natureza, como fundamento de suas respectivas concepções de mundo. Na investigação heideggeriana a natureza não é, então, o ente que pode tomar compreensivel a mundanidade do mundo. Mundo é um conceito ontológico, enquanto tal só pode ser elucidado na medida em que for levada em conta a constituição do modo de ser do ente que é ser-no-mundo.

Característica essencial do Dasein, constitutiva do modo de ser deste ente, a base unitária ser-no-mundo se articula em ser-com (mit-Sein) outros entes que possuem o mesmo modo de ser do Dasein, e ser-junto (Sein bei) dos entes que não possuem a peculiaridade do Dasein, entes que são encontrados no mundo, ou entes intramundanos. Se as características do modo de ser do Dasein são denominadas existenciais, as do ente intramundano recebem em Sein und Zeit a denominação de categorias. Mas, convém lembrar que, em Sein und Zeit, o termo categoria significa: "dizer na cara dos entes o que, como ente, cada um deles é, ou seja, deixar e fazer todos verem o ente em seu ser"15.

A analítica porém, não tira o seu fio condutor de nenhuma diferença entre o Dasein e os entes intramundanos, pois não se trata do conhecimento de duas modalidades diferentes de ser. Se trata, ao invés disto, de interpretar o modo de ser do Dasein, com o que, a analítica pode extrair seu fio condutor do "modo indiferente no qual, de início e mais seguidamente", ${ }^{16}$ o Dasein aparece na banalidade quotidiana, e isto por considerá-la caráter fenomenal positivo. É a indiferença quotidiana, modo ôntico do Dasein, que serve pois de guia para a descrição fenomenológica de seu modo de ser.

Quanto aos entes intramundanos, a analítica não se dedica ao seu estudo visando o conhecimento de propriedades ônticas que lhes pudessem convir, como por exemplo, a substancialidade, a matéria, a extensão ou a justaposição. As categorias (Kategorien) do ente intramundano ${ }^{17}$ não são lógicas, são ontológicas, dizem respeito ao seu modo de ser, sempre já conexo à constiuição do ser do Dasein. A interpretação fenomenológico-hermenêutica encontra o ser-no-mundo no modo da ocupação (Bessorgen) na qual o ente intramundano se acha inserido,

\footnotetext{
SZ, p. 44; ST p. 81.

$S Z$, p. $43 ; S T$ p.

É importante enfatizar o sentido que Heidegger atribui ao termo categona, "Numa perspectiva ontológica, a palavra significa: dizer na cara dos entes o que, como ente, cada um deles é, ou seja, deixar e fazer todos verem 0 ente em seu ser". Cf. SZ, p.44,45; ST,p. 81.
} 
mas não primeiramente como simples presença (Vorhandenheit), ou ente simplesmente dado ao conhecimento. Ao invés disto, no mundo ambiente (Umwelt) da quotidianidade média do Dasein, o ente intramundano é encontrado no âmbito da circunvisão (Umsicht) da ocupação como instrumento (Zeug) que serve para a lida de todo dia.

Com o intuito de não forçar o acesso ao ser do ente intramundano é que sua descrição por parte da fenomenologia hermenêutica não o separa nem da estrutura dos reenvios constitutivos do seu modo de ser, nem da compreensão do Dasein, com o que, a descrição da relação entre Dasein e ente intramundano propicia ver que o ser-útil do instrumento (Zuhandenheit), sua estrutura ontológica, é tanto mais acessivel, quanto menos este ente se destaca da rede de reenvios inerente à totalidade significativa na qual ele se encontra inserido. Para a analítica existencial, isto significa que Dasein e ente intramundano se encontram já sempre numa relação originária fundada não em algum tipo de experiência perceptiva, mas na pré-estrutura (Vorstruktur) compreensivo-interpretativa constitutiva do Dasein.

Através da hermenêutica dos momentos estruturais constitutivos do ser-nomundo, as categorias relativas ao ente intramundano são, portanto, deslocadas do campo da lógica, no qual tradicionalmente foram enfocadas, para o âmbito préontológico de sua revelação originária, ou seja, para a pré-compreensão do Dasein. A tematização nela fundada oferece, dentre outros, os seguintes resultados: compreensão (Verstehe), e disposição (Befindlichkeit) são cooriginariamente constitutivas do modo de ser do Dasein porque são responsáveis pela sua abertura, tanto na descoberta do ente intramundano, quanto pela revelação do "si mesmo". Esta cooriginariedade redimensiona o que a tradição tratou por sensibilidade, ao tempo em que mostra que a compreensão ontológica não é fruto de nenhuma intelecção mas que ela é sempre afetivamente tonalizada; o liame que vincula a compreensão à interpretação (Auslegung) mostra, por sua vez, que esta última não é decorrente de um tipo qualquer de conhecimento mas é o desenvolvimento da compreensão da significação de ser-no-mundo.

Os modos existenciais da disposição, da compreensão com o seu desenvolvimento na interpretação, esclarecem pois, em Sein und Zeit, o modo de ser originário do Dasein, o "como" ele é, enquanto é ser- no- mundo. A este ente pertence ontológicamente, a visão compreensivo-interpretativa e cooriginariamente sentida que comparece na analítica existencial como uma pré-estrutura: posição prévia (Vorhabe), visão-prévia (Vorsicht), concepção prévia (Vorgniff). Através desta préestrutura, o problema do conhecimento ontológico, hermenêutico-fenomenológico de Sein und Zeit, pode receber sua explicitação: "interpretar não é tomar conhecimento do que se compreendeu, mas elaborar as possibilidades projetadas na compreensão". ${ }^{18}$

Por isto, quando em Sein und Zeit a interpretação vem tematizada, Heidegger declara que toda visão antepredicativa do que está à mão já é em si mesma com-

SZ, p. 148; ST, p. 204. 
preensão e interpretação. Isto quer dizer que a pré-compreensão originánia, visão pré-ontológica do ser pertencente ao Dasein, é antepredicativa porque tem suas raízes na constituição do modo de ser do Dasein e não em alguma forma do representar ou do intuir.Sendo assim, a estrutura do "como" da interpretação, que acede explicitamente à visão compreensiva, não precisa necessariamente, tomar explícito numa proposição aquilo que foi interpretado na circunvisão, porque a proposição é derivada da interpretação. Conseqüentemente, a explicitação através da proposição pode faltar sem que com isto nos encontremos diante da pura e simples percepção de alguma coisa. E isto, justamente porque a visão antepredicativa já é compreensivo-intepretativa, isto é, já é articulada, não sendo necessário submetê-la por acréscimo a nenhum tipo de operação lógico-categorial.

A peculiaridade do conhecimento ontológico, que em Sein und Zeit passa necessariamente pela analítica da existência, é o de ser hermenêutico na medida em que ele desenvolve, se apropria e radicaliza a pré-compreensão característica do Dasein sem transformá-la noutra coisa que não seja ela mesma.

Por sua vez, o acesso ao "como" hermenêutico, entendido como conversão do olhar, do ente ao ser, sentido específico que Heidegger confere à redução fenomenológica, faz com que os conceitos de sua ontologia sejam conceitos hermenêuticos. A hermenêutica heideggeriana em Sein und Zeit se configura então, numa interpretação fenomenológica, fundada na visão compreensivo-interpretativa e cooriginariamente sentida, característica do modo de ser do Dasein, cuja constituição antecipa, ou é fundante, da própria ontologia fundamental.

Se a disposição, a compreensão e a interpretação originárias do ente intramundano se encontram articuladas pela visão do Dasein que não apresenta as marcas distintivas da representação ou da intuição e, tão pouco pode ser circunscrita à percepção uma vez que não a requer, nem estruturalmente, nem teleologicamente, os conceitos da ontologia fundamental só podem ser extraídos do solo antepredicativo segundo Heidegger o entende, ou seja na sua dimensão existencial e não lógico-categorial. 